Tropical Journal of Pharmaceutical Research May 2015; 14(5): 869-878

ISSN: $1596-5996$ (print); 1596-9827 (electronic)

(C) Pharmacotherapy Group, Faculty of Pharmacy, University of Benin, Benin City, 300001 Nigeria.

All rights reserved.

Available online at http://www.tjpr.org

Original Research Article

http://dx.doi.org/10.4314/tjpr.v14i5.18

\title{
Simultaneous Determination of Flavonols and Terpene Lactones in Beagle Dog Plasma by Ultra-Performance Liquid Chromatography-Tandem - Mass Spectrometry: 1. Method Development
}

\author{
Yang Lu, Pengyue Li, Huimin Liu, Shouying Du*, Yanke Cheng, Huichao Wu, \\ Jiannan Feng and Beibei Shao \\ School of Chinese Materia Medica, Beijing University of Chinese Medicine, Beijing 100102, China
}

*For correspondence: Email: dushouying@263.net; Tel: 86-010-84738615

Received: 25 August 2014

Revised accepted: 4 April 2015

\begin{abstract}
Purpose: To develop an ultra-performance liquid chromatography-tandem mass spectrometry (UPLCMS/MS) method for the simultaneous determination of 7 major components of Ginkgo leaf (kaempferol, quercetin, isorhamnetin, ginkgolides A, ginkgolides B, ginkgolides $C$ and bilobalide) in dog plasma. Methods: Beagle dog plasma samples were spiked with internal standard (domperidone), acidified with $\mathrm{HCl}$ and extracted twice by liquid-liquid extraction using ethyl acetate. Chromatographic separation was achieved on an Acquity UPLC BEH C18 column $(100 \times 2.1 \mathrm{~mm}, 1.7 \mu \mathrm{m})$ by gradient elution with a run time of 4.0 min. The specificity, linearity, precision, recovery, matrix effect and stability of the method were determined.

Results: The method showed high selectivity of the flavonols and terpene lactones in plasma samples. The concentration of the 7 target compounds showed good linear relationship with the peak area ratios of each analyte to internal standard. Lower limit of quantification (LLOQ) was 1.232, 0.240, 0.200 , 1.330, 0.960, 0.696, $0.470 \mathrm{ng} \cdot \mathrm{mL}^{-1}$ for kaempferol, quercetin, isorhamnetin, bilobalide, ginkgolides A, ginkgolides $B$ and ginkgolides C, respectively. Recovery of all QC samples ranged from 77.68 to 105.07 $\%$. Matrix effect derived from QC samples was in the range of $85.09-113.14 \%$. The stability of the analytes, calculated as RSD at three concentrations, was $<15 \%$.

Conclusion: The developed method is simple, rapid and sensitive and can be applied to the determination of kaempferol, quercetin, isorhamnetin, ginkgolides $A$, ginkgolides $B$, ginkgolides $C$ and bilobalide in dog plasma.
\end{abstract}

Keywords: Ultra-performance liquid chromatography-tandem mass spectrometry, Ginkgo biloba, Beagle dog plasma, Kaempferol, Quercetin, Isorhamnetin, Ginkgolides A, Ginkgolides B, Ginkgolides C, Bilobalide

Tropical Journal of Pharmaceutical Research is indexed by Science Citation Index (SciSearch), Scopus, International Pharmaceutical Abstract, Chemical Abstracts, Embase, Index Copernicus, EBSCO, African Index Medicus, JournalSeek, Journal Citation Reports/Science Edition, Directory of Open Access Journals (DOAJ), African Journal Online, Bioline International, Open-J-Gate and Pharmacy Abstracts

\section{INTRODUCTION}

The extract of Ginkgo biloba (Ginkgo, Ginkgoaceae) leaves has been considered as valuable medicine and dietary supplements for more than 40 years. Pharmacology experiments showed that it is helpful to the prevention and treatment of cardiovascular diseases [1,2] and cerebral insufficiency [3-7]. Such pharmacological activities are attributed to the flavonoid glycosides and terpene lactones. 
According to the Food and Drug Administration of the United States, botanical drug products should be investigated with regard to blood levels of known representative markers, active constituents, and major chemical constituents.

In this study, a simple, rapid and sensitive ultraperformance liquid chromatography-tandem mass spectrometry (UPLC-MS/MS) method was developed for the simultaneous determination of the 7 major components Ginkgo Biloba leaves (kaempferol, quercetin, isorhamnetin, ginkgolides A, ginkgolides $\mathrm{B}$, ginkgolides $\mathrm{C}$ and bilobalide) in dog plasma.

\section{EXPERIMENTAL}

\section{Chemicals}

The reference standards of kaempferol (KMF), quercetin (QCT), isorhamnetin (ISR), ginkgolides A (GA), ginkgolides $B(G B)$, ginkgolides $C(G C)$ and bilobalide (BB) and domperidone (DPD) (IS) were purchased from the National Institute for the Control of Pharmaceutical and Biological Products (Beijing, China). The purity of QCT and GC was 96.5 and $97.1 \%$, respectively. The purity of the remaining reference standards was more than $99 \%$. LC/MS grades of methanol and acetonitrile were obtained from Fisher Scientific (Fair Lawn, NJ, USA), HPLC grade of formic acid was supplied by ROE Scientific (Newcastle, USA), and ultrapure water was generated from the Synergy UV water purification system (Millipore Corp, USA).

\section{Instrumentation and chromatographic conditions}

The UPLC-MS/MS system used was composed of an Acquity UPLC system (Waters Corp., Milford, MA, USA) and a TQS triple quadrupole tandem mass spectrometer (Waters Corp., Milford, MA, USA) equipped with an electrospray ionization (ESI) source. Data were acquired and processed using MassLynx 4.1 software (Waters Corp., Milford, MA, USA).
Chromatographic separation was performed on an ACQUITY UPLC BEH C18 column $(100 \mathrm{~mm} \times$ $2.1 \mathrm{~mm} I \mathrm{D}, 1.7 \mu \mathrm{m}$; Waters Corp., Milford, MA, USA). The column temperature was maintained at $40{ }^{\circ} \mathrm{C}$ and the auto-sampler was conditioned at $4{ }^{\circ} \mathrm{C}$. The mobile phase was composed of 0.1 $\%$ formic acid aqueous solution (A) and acetonitrile (B) at a flow rate of $0.4 \mathrm{~mL} / \mathrm{min}$ in only 4.0 minutes. Gradient condition of the mobile phase was as follows: $5 \% \mathrm{~B}$ at $0-1.0$ $\min ; 5 \rightarrow 40 \%$ B at $1.0-1.5 \mathrm{~min} ; 40 \% \rightarrow 43 \%$ B at $1.5-3.0 \mathrm{~min}$, then the system was equilibrated using the initial condition (acetonitrile-water, $5: 95, \mathrm{v} / \mathrm{v}$ ) for $1.0 \mathrm{~min}$. The injection volume was 3 $\mu \mathrm{L}$ and the partial loop with a needle overfill mode was used for sample injection.

Mass spectrometer was operated in the negative ion mode using a multiple reaction monitoring (MRM) approach. Cone voltage was set at $30 \mathrm{~V}$, and source and desolvation temperatures were set at 150 and $400{ }^{\circ} \mathrm{C}$, respectively. Nitrogen was used as the desolvation gas and cone gas with the flow rates of 800 and $150 \mathrm{~L} / \mathrm{h}$, respectively. Argon was used as the collision gas at a pressure of approximately $3.4 \times 10^{-3}$ mbar. The specific parameters for each analyte are shown in Table 1.

\section{Preparation of standards and quality control}

Seven separate primary stock solutions for KMF, QCT, ISR, BB, GA, GB, and GC were prepared by dissolving the accurately weighed reference compounds in methanol at the concentrations of $110,125,123,104,100,145,147 \mu \mathrm{g} / \mathrm{mL}$, respectively. The stock solutions were then mixed together and serially diluted with methanol to produce a series of standard or quality control (QC) working solutions at the desired concentrations.

DPD (IS) was also prepared as a stock solution of $192 \mu \mathrm{g} / \mathrm{mL}$ in methanol and diluted with methanol to yield a working solution of 576 $\mathrm{ng} / \mathrm{mL}$.

Table 1: Optimized mass parameters for flavonols, terpene lactones and internal standard

\begin{tabular}{lcccccc}
\hline Compound & $\begin{array}{c}\text { Scan } \\
\text { type }\end{array}$ & Precursor ion & $\begin{array}{c}\text { Product } \\
\text { ion }\end{array}$ & $\begin{array}{c}\text { Cone } \\
\text { voltage } \\
\text { (V) }\end{array}$ & $\begin{array}{c}\text { Collision } \\
\text { energy } \\
\text { (eV) }\end{array}$ & $\begin{array}{c}\text { Polarity } \\
\text { KMF }\end{array}$ \\
QCT & MRM & 284.954 & 150.930 & 76 & 20 & Negative \\
ISR & MRM & 301.072 & 150.929 & 54 & 18 & Negative \\
BB & MRM & 315.018 & 300.031 & 68 & 20 & Negative \\
GA & MRM & 325.132 & 163.033 & 30 & 20 & Negative \\
GB & MRM & 407.172 & 315.129 & 54 & 14 & Negative \\
GC & MRM & 423.172 & 367.131 & 22 & 16 & Negative \\
DPD (IS) & MRM & 439.098 & 383.129 & 2 & 36 & Negative \\
\hline
\end{tabular}


All these solutions were stored at $4{ }^{\circ} \mathrm{C}$ and brought to room temperature before the solutions were used.

The calibration samples were prepared by spiking $500 \mu \mathrm{L}$ blank beagle dog plasma with 20 $\mu \mathrm{L}$ standard working solutions and $20 \mu \mathrm{L}$ IS working solutions to obtain final concentrations of $1.232,3.08,6.16,15.4,30.8,77.0,154.0,385.0$, and $770.0 \mathrm{ng} / \mathrm{mL}$ for KMF; $0.24,0.6,1.2,3.0$, $6.0,15.0,30.0,75.0$, and $150.0 \mathrm{ng} / \mathrm{mL}$ for QCT; $0.197,0.492,0.984,2.46,4.92,12.324 .6,61.5$, and $123.0 \mathrm{ng} / \mathrm{mL}$ for ISR; $1.331,3.328,6.656$, $16.64,33.28,83.2,166.4,416.0$, and 832.0 $\mathrm{ng} / \mathrm{mL}$ for BB; $0.96,2.4,4.8,12.0,24.0,60.0$, $120.0,300.0$, and $600.0 \mathrm{ng} / \mathrm{mL}$ for GA; 0.696 , $1.74,3.48,8.7,17.4,43.5,87.0,217.5$, and $435.0 \mathrm{ng} / \mathrm{mL}$ for GB; and $0.470,1.176,2.352$, $5.88,11.76,29.4,58.8,147.0$, and $294.0 \mathrm{ng} / \mathrm{mL}$ for GC. Low-, medium-, and high-level QC samples were also prepared in the same way to obtain concentrations of $3.08,30.8$, and 616 $\mathrm{ng} / \mathrm{mL}$, respectively, for KMF; 0.6, 6.0, and 120 $\mathrm{ng} / \mathrm{mL}$, respectively, for QCT; $0.492,4.92$, and $98.4 \mathrm{ng} / \mathrm{mL}$, respectively, for ISR; 3.328, 33.28, and $665.6 \mathrm{ng} / \mathrm{mL}$, respectively, for BB; 2.4, 24.0, and $480 \mathrm{ng} / \mathrm{mL}$, respectively, for GA; 1.74, 17.4, and $348 \mathrm{ng} / \mathrm{mL}$, respectively, for GB; and 1.176, 11.76 , and $235.2 \mathrm{ng} / \mathrm{mL}$, respectively, for GC.

\section{Animals and sample handling}

Male adult beagle dogs (SPF animal, $11.1 \pm 0.3$ $\mathrm{kg}$, certificate number SCXK (Jing) 2013-0007) were obtained from the Beijing Tongli experimental animal farms. Animals were housed in a temperature-controlled house. Water and standard laboratory food were available ad libitum. The experimental protocols were conducted in accordance with The Guiding Principles for the Care and Use of Laboratory Animal (published by Ministry of Science and Technology of the People's Republic of China, Chapters 2, 3 and 5) and were approved by the Institutional Animal Care and Use Committee of the Beijing University of Chinese Medicine.

Blood samples were collected before and after the drug administration. The steps of the sample treatments are described as follows: $500 \mu \mathrm{L}$ plasma was placed in an Eppendorf tube; then $20 \mu \mathrm{L}$ of IS solution and $500 \mu \mathrm{L}$ of $25 \%$ hydrochloric acid were added to the tube and the mixture was vortex mixed for $1 \mathrm{~min}$. Then the plasma sample was hydrolyzed for $30 \mathrm{~min}$ in a water bath at $80{ }^{\circ} \mathrm{C}$, and the hydrolyzed and cooled sample was vortex mixed for 3 min after adding $2.0 \mathrm{~mL}$ acetidin. The mixture was centrifuged at $8000 \mathrm{rpm}$ for $10 \mathrm{~min}$ to separate the water phase from the organic phase (I). The water phase was repeatedly spiked with $2 \mathrm{~mL}$ acetidin by vortex mixing for $3 \mathrm{~min}$ and centrifuged at $8000 \mathrm{rpm}$ for $10 \mathrm{~min}$ to separate the water phase from the organic phase (II). The organic phase (I) and the organic phase (II) were put together and transferred to a clean centrifuge tube. The mixture was evaporated to dryness under a gentle stream of nitrogen. The residue was reconstituted with $200 \mu \mathrm{L}$ methanol; then the solution was centrifuged at $12000 \mathrm{rpm}$ for 15 min, and finally, an aliquot of $3 \mu \mathrm{L}$ of the solution was injected into the chromatographic system for measurements.

\section{Method validation}

\section{Selectivity}

Selectivity was evaluated by comparing the chromatograms of six individual blank dog plasma samples with those of corresponding standard plasma samples spiked with the analytes and IS, and plasma samples obtained after oral administration of drugs.

\section{Calibration curves and $L L O Q$}

To evaluate linearity, the calibration curves were confirmed by plotting the peak area ratios of each analyte to IS versus the concentration of calibration samples through the linear least squares regression calculation with the suitable weighting factor of $1 / x$. A correlation coefficient (r) should be greater than 0.99 for assessment of linearity. The concentrations of QC samples or the test samples were calculated using the regression equations gained from the calibration curves. The LLOQ for the analytes were the lowest concentration point of the calibration curve. Analytes response at the level of LLOQ should be at least five times that of the blank plasma.

\section{Recovery and matrix effect}

The extraction recoveries and matrix effects of analytes were determined by analyzing six replicates of QC samples at three concentration levels. The extraction recoveries were calculated by comparing the response obtained from QC samples spiked before extraction with those from QC samples spiked in post-extracted blank dog plasma at the same concentrations. The matrix effects were evaluated by comparing the response obtained from QC samples spiked post-extraction blank dog plasma with those from QC samples spiked in before extracted pure water at the same concentrations. The matrix 
effects should be neglected if the ratio is in the range of $85-115 \%$.

\section{Intra- and inter-day precision}

Precision were evaluated by analysis of $Q C$ samples at low, medium and high concentrations with six replicates on the same day and three consecutive days. Precision was expressed as the intra- and inter-day RSD. The precisions were required to be less than $15 \%$, except for the low QC samples where the precision should be below $20 \%$.

\section{Stability studies}

Stability studies were conducted at three QC levels with three replicates in different conditions that occurred during sample analysis. The shortterm stability was evaluated with QC samples stored at room temperature for $6 \mathrm{~h}$. The longterm stability was assessed by QC samples kept at $-80{ }^{\circ} \mathrm{C}$ for 1 month. The post-preparative stability was measured by determining QC samples maintained in the auto-sampler conditions at $4{ }^{\circ} \mathrm{C}$ for $12 \mathrm{~h}$. The samples were considered to be stable if the deviation from the nominal concentration was within the acceptable limits of $\pm 15 \%$.

\section{RESULTS}

\section{Specificity and selectivity}

Fig 1 showed the representative chromatograms of blank plasma sample, Fig 2 showed the chromatograms of plasma sample spiked with KMF (2.79 min), QCT (2.53 min), ISR (2.86 min), BB (2.42 min), GA (2.61 min), GB (2.60 min), GC (2.34 $\mathrm{min})$, and IS (2.35 $\mathrm{min})$, Fig 3 showed the chromatograms of plasma sample at $120 \mathrm{~min}$ after oral administration of Ginkgo leaf extraction preparations. The chromatograms from the bottom up in proper order are: KMF, QCT, ISR, $\mathrm{BB}, \mathrm{GA}, \mathrm{GB}, \mathrm{IS}$ and GC, respectively.

\section{Linearity and LLOQ}

Table 2 lists the regression equation, correlation coefficients, linearity ranges, and LLOQ of the analytes. All calibration curves exhibited good linearity with the correlation coefficients $(r)$ higher than 0.9952. The LLOQ were 1.232, 0.240, $0.200,1.3300 .960,0.696$, and $0.470 \mathrm{ng} / \mathrm{mL}$ for KMF, QCT, ISR, BB, GA, GB, and GC, respectively.

The calibration curves were confirmed by plotting the peak area ratios of each analyte to IS versus the concentration of calibration samples through the linear least squares regression calculation with the suitable weighting factor of $1 / x$.

\section{Recovery and matrix effect}

The extraction recoveries and matrix effects of all analytes at different levels of concentrations are shown in Table 3. The recoveries of three-level QC samples ranged from $77.68 \%$ to $105.07 \%$. The matrix effects derived from QC samples were in the range of $85.09 \%-113.14 \%$. The results showed that the plasma matrix effect was negligible under the current conditions.

\section{Intra- and inter-day precision}

The intra- and inter-day precisions are shown in Table 4. The precisions of KMF, QCT, ISR, BB, $\mathrm{GA}, \mathrm{GB}$, and GC calculated as the RSD at three concentrations were lower than $10 \%$ for intraand inter-day assays for quality control. The results demonstrated that the precision of this method was acceptable.

\section{Stability}

The stability experiments aimed at testing samples under all possible conditions the samples might experience after collection and prior to analysis. The summaries are listed in Table 5. The stability of the analytes calculated as the RSD at three concentrations was lower than $15 \%$ for quality control. The results demonstrated that the precision of the study was acceptable.

\section{DISCUSSION}

The method to determine the flavonol aglycones QCT, KMF, and ISR in G. biloba products was completed by a single laboratory validation [8], and the method was evaluated in the collaborative laboratory in 2007 [9]. A rapid quantitative analysis of GA, GB, GC, and GJ, and $B B$ in ginkgo dietary supplements was established [10]. Up to now it is known that an LC-MS/MS was developed for simultaneous measurement of eight ginkgo flavonoids (QCT, $\mathrm{KMF}$, and ISR) and terpenoids (BB, GA, GB, GC, and $G J$ ) in vitro [11]. In a more recent study, on the basis of LC-MS/MS working in the MRM mode, an analytical method was established to simultaneously determine 24 main bioactive components, including flavonol glycosides, terpene lactones, biflavones, proanthocyanidins, and ginkgolic acids in G. biloba leaves [12]. FDA 
09:24:38

20130618_03

MRIM of 8 Channels ES-

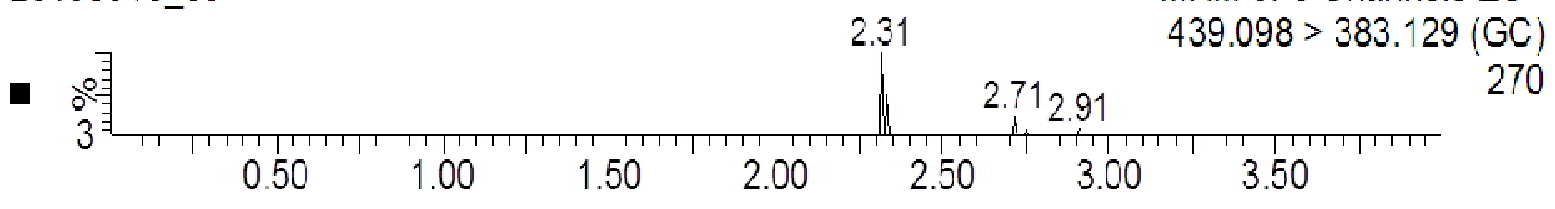
20130618_03

MRIM of 8 Channels ES-

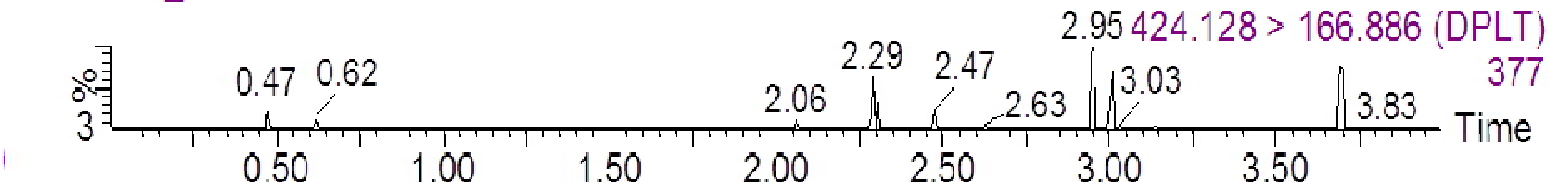

20130618_03

MRM of 8 Channels ES-

踭<smiles>C1CCCC1</smiles>
(20)
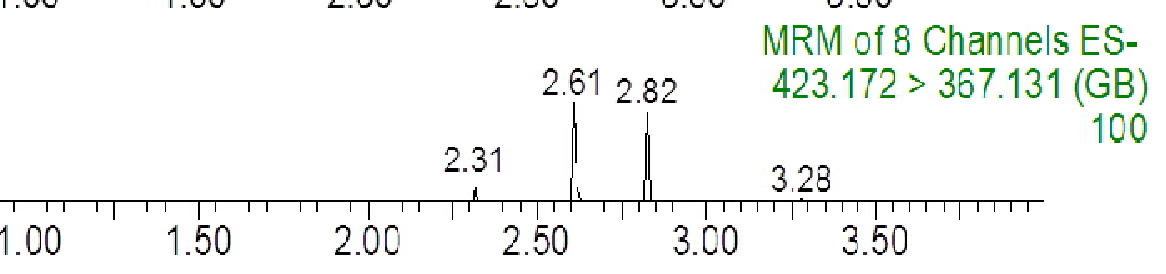

20130618_03

$\begin{array}{lllllllll}0.50 & 1.00 & 1.50 & 2.00 & 2.50 & 3.00 & 3.50\end{array}$

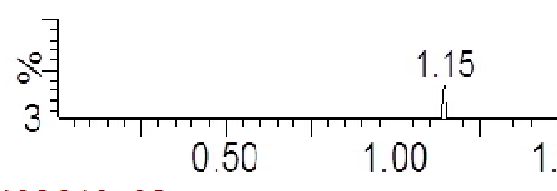

201306

MRM of 8 Channels ES-

$407.108>351.129(\mathrm{GA})$

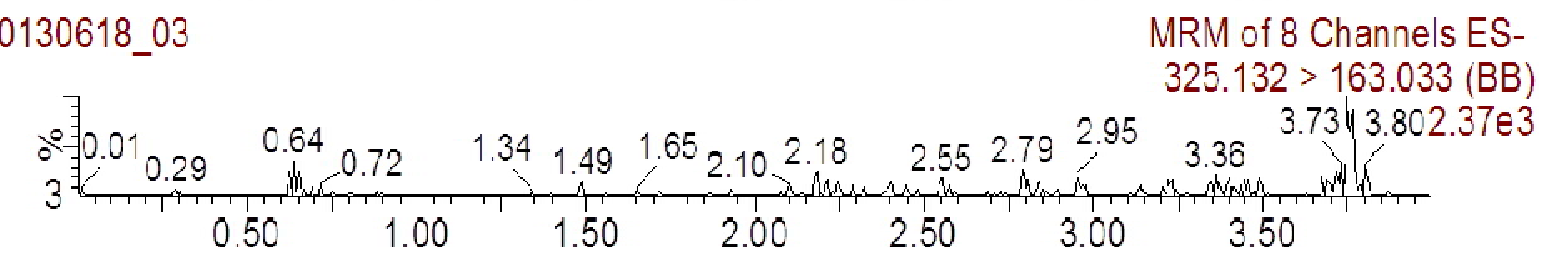

20130618_03 MRM of 8 Channels ES-

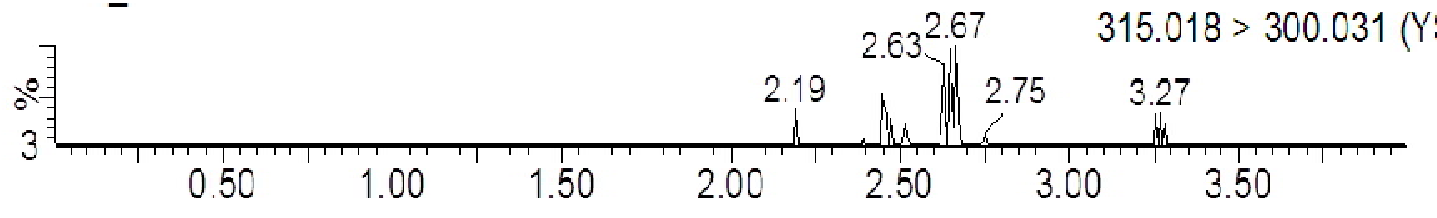

20130618_03

MRM of 8 Channels ES-

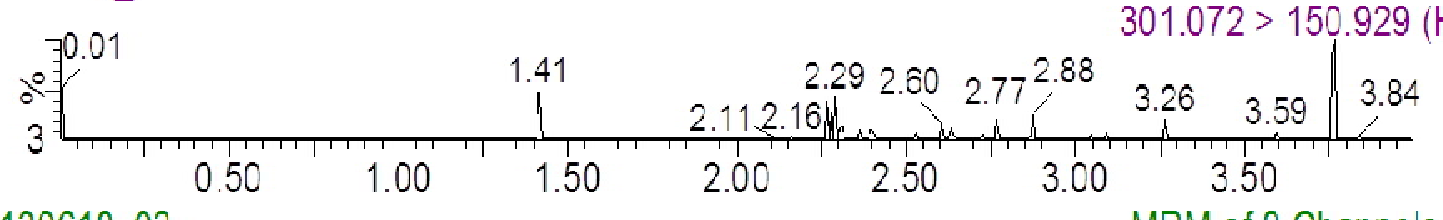

727

20130618

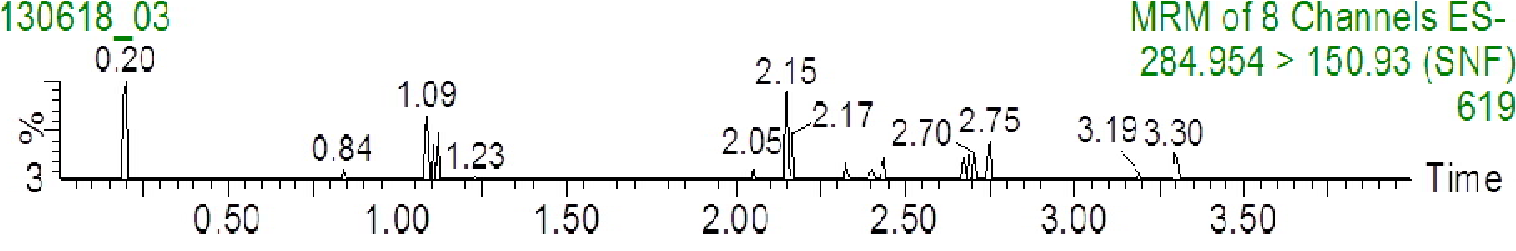

Fig 1: Chromatogram of blank plasma sample 


\section{1:15:01}

20130603_112

MRM of 8 Channels ES-

只毒 20130603_112

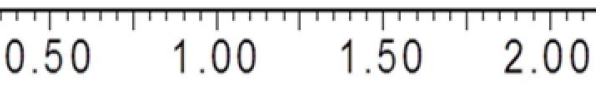

$$
3
$$

욜
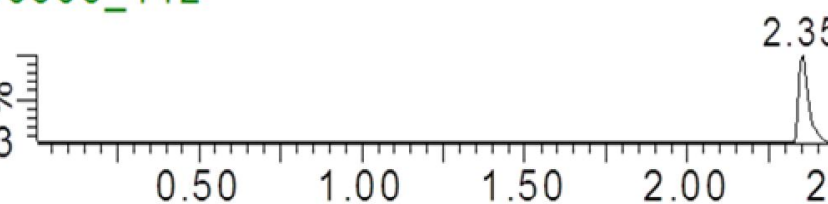

\section{3_112}

3

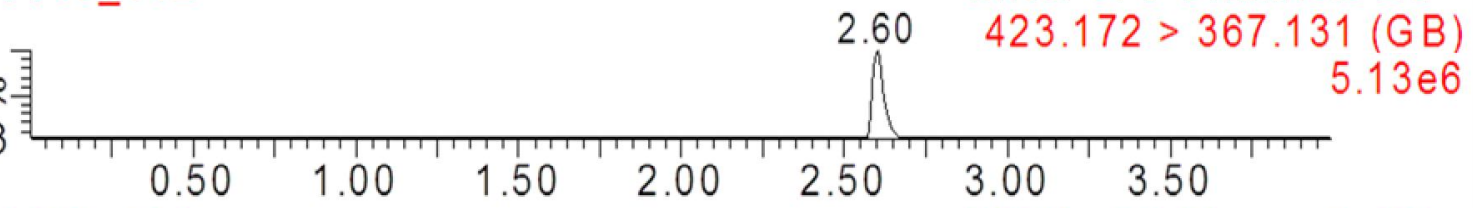
20130603_112

MRM of 8 Channels ES-

ㅇํㄹ

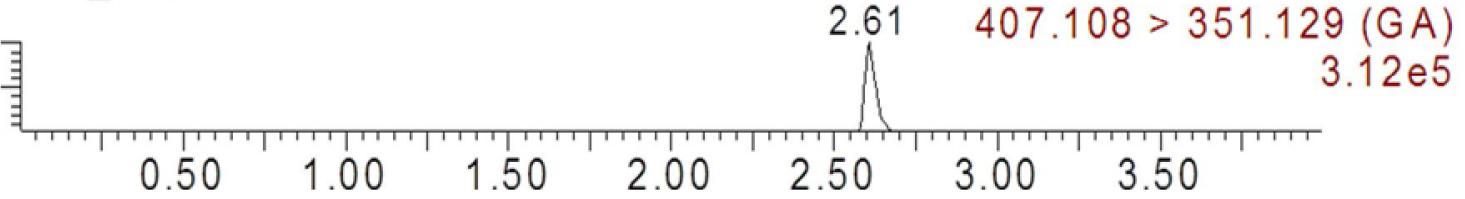
20130603_112

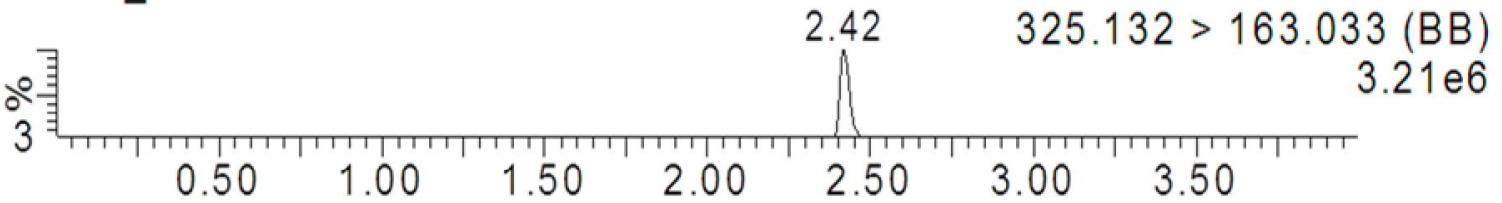
20130603_112

율
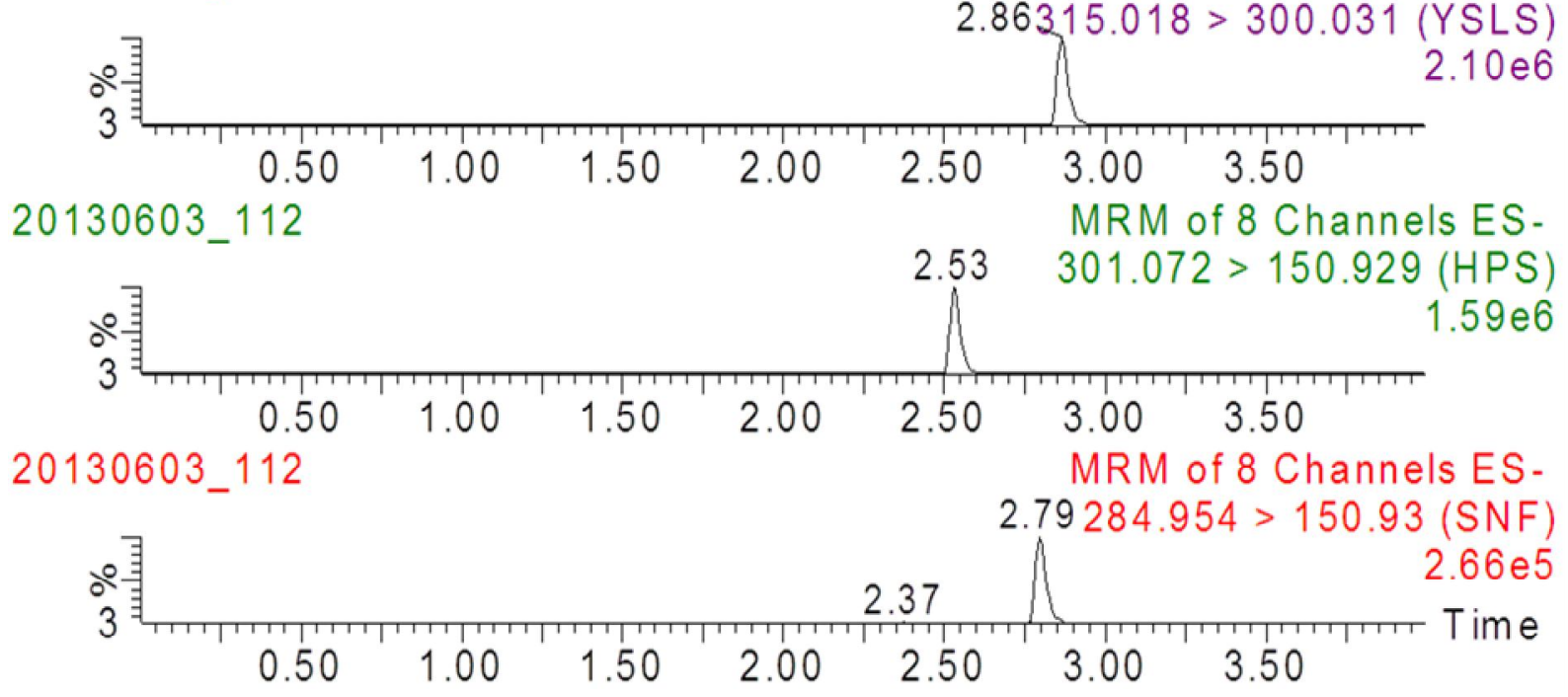

Fig 2: Chromatograms of blank plasma sample spiked with the seven Ginkgo components and IS 


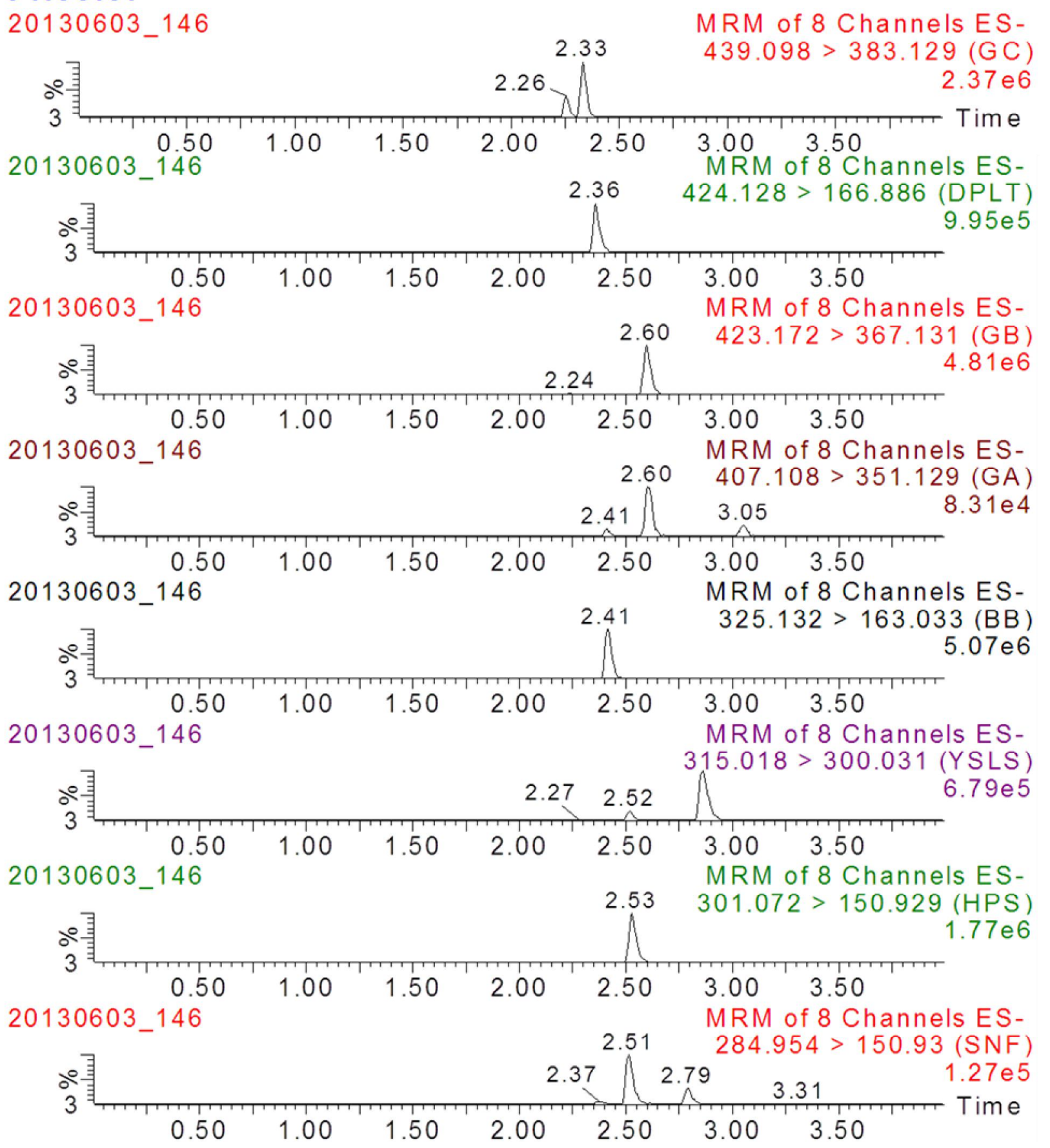

Fig 3: Chromatograms of plasma sample from a beagle dog at $120 \mathrm{~min}$ after a single oral administration of ginkgo leaf extraction preparation

Table 2: Regression data and LLOQ of the analytes

\begin{tabular}{|c|c|c|c|c|}
\hline Compound & The Regression Equation & $\mathbf{r}$ & $\begin{array}{l}\text { Linearity Ranges } \\
\left(\mathrm{ng} \cdot \mathrm{mL}^{-1}\right)\end{array}$ & LLOQ \\
\hline KMF & $Y=0.1644 X \pm 0.2500$ & 0.9994 & $1.232 \sim 770$ & 1.232 \\
\hline QCT & $Y=4.1719 X \pm 0.2012$ & 0.9987 & $0.240 \sim 150$ & 0.240 \\
\hline ISR & $Y=9.0977 X \pm 0.9591$ & 0.9995 & $0.200 \sim 123$ & 0.200 \\
\hline BB & $Y=0.4310 X+1.0351$ & 0.9993 & $1.330 \sim 832$ & 1.330 \\
\hline GA & $Y=0.0425 X+0.0937$ & 0.9952 & $0.960 \sim 600$ & 0.960 \\
\hline GB & $Y=3.6240 X+6.7713$ & 0.9956 & $0.696 \sim 435$ & 0.696 \\
\hline GC & $Y=2.2237 X+1.2385$ & 0.9987 & $0.470 \sim 294$ & 0.470 \\
\hline
\end{tabular}


Table 3: Extraction recovery and matrix effect of the analytes in beagle dog plasma $(n=6)$

\begin{tabular}{|c|c|c|c|c|c|}
\hline \multirow{2}{*}{ Compound } & \multirow{2}{*}{$\begin{array}{c}C \\
\left(n g \cdot m L^{-1}\right)\end{array}$} & \multicolumn{2}{|c|}{ Extraction recovery } & \multicolumn{2}{|c|}{ Matrix effect } \\
\hline & & $(\%$, mean \pm SD $)$ & RSD\% & $(\%$, mean \pm SD $)$ & RSD\% \\
\hline & 3.08 & $103.16 \pm 8.17$ & 8.02 & $95.13 \pm 4.78$ & 5.01 \\
\hline \multirow{3}{*}{ KMF } & 30.8 & $79.63 \pm 3.91$ & 4.92 & $99.97 \pm 5.18$ & 5.18 \\
\hline & 616 & $84.78 \pm 3.67$ & 4.32 & $92.66 \pm 3.18$ & 3.59 \\
\hline & 0.6 & $92.04 \pm 4.27$ & 4.63 & $105.21 \pm 11.43$ & 10.79 \\
\hline \multirow[t]{3}{*}{ QCT } & 6 & $83.50 \pm 9.55$ & 11.38 & $96.10 \pm 13.00$ & 13.94 \\
\hline & 120 & $83.29 \pm 4.76$ & 5.70 & $86.12 \pm 3.23$ & 3.95 \\
\hline & 0.492 & $87.92 \pm 17.07$ & 19.55 & $100.14 \pm 5.76$ & 5.73 \\
\hline \multirow[t]{3}{*}{ ISR } & 4.92 & $81.00 \pm 9.57$ & 11.93 & $98.42 \pm 5.08$ & 10.63 \\
\hline & 98.4 & $81.19 \pm 2.26$ & 2.78 & $94.88 \pm 8.53$ & 3.49 \\
\hline & 3.328 & $104.33 \pm 5.68$ & 5.44 & $98.42 \pm 5.08$ & 5.16 \\
\hline \multirow[t]{3}{*}{ BB } & 33.28 & $84.95 \pm 8.43$ & 9.85 & $94.88 \pm 8.53$ & 8.99 \\
\hline & 665.6 & $80.21 \pm 0.94$ & 1.17 & $97.43 \pm 1.43$ & 1.47 \\
\hline & 2.4 & $100.64 \pm 7.87$ & 7.84 & $97.32 \pm 5.95$ & 6.10 \\
\hline \multirow[t]{3}{*}{ GA } & 24 & $81.71 \pm 8.32$ & 9.50 & $99.80 \pm 4.71$ & 4.60 \\
\hline & 480 & $87.09 \pm 4.33$ & 4.97 & $91.76 \pm 3.39$ & 3.69 \\
\hline & 1.74 & $94.98 \pm 8.94$ & 9.43 & $113.14 \pm 2.22$ & 1.96 \\
\hline \multirow[t]{3}{*}{ GB } & 17.4 & $80.20 \pm 10.87$ & 13.45 & $89.80 \pm 9.04$ & 10.05 \\
\hline & 348 & $77.86 \pm 6.66$ & 8.50 & $85.09 \pm 6.49$ & 8.18 \\
\hline & 1.176 & $105.07 \pm 5.00$ & 4.75 & $93.62 \pm 3.84$ & 4.10 \\
\hline \multirow[t]{2}{*}{ GC } & 11.76 & $97.91 \pm 6.26$ & 6.38 & $98.61 \pm 7.65$ & 7.74 \\
\hline & 235.2 & $95.46 \pm 2.64$ & 2.77 & $103.09 \pm 1.41$ & 1.35 \\
\hline
\end{tabular}

Table 4: Precision of seven components in beagle dog plasma

\begin{tabular}{|c|c|c|c|}
\hline Compound & $\begin{array}{c}\mathrm{C} \\
\left(\mathrm{ng} \cdot \mathrm{mL}^{-1}\right)\end{array}$ & Intraday $(n=6)$ & Interday $(n=18)$ \\
\hline & 3.08 & 13.58 & 5.67 \\
\hline \multirow{3}{*}{ KMF } & 30.8 & 5.81 & 5.46 \\
\hline & 616 & 12.11 & 2.35 \\
\hline & 0.6 & 15.57 & 3.38 \\
\hline \multirow[t]{3}{*}{ QCT } & 6 & 13.98 & 7.37 \\
\hline & 120 & 9.56 & 9.78 \\
\hline & 0.492 & 9.79 & 6.14 \\
\hline \multirow[t]{3}{*}{ ISR } & 4.92 & 14.22 & 5.82 \\
\hline & 98.4 & 13.26 & 1.37 \\
\hline & 3.328 & 9.36 & 2.71 \\
\hline \multirow[t]{3}{*}{ BB } & 33.28 & 4.55 & 6.50 \\
\hline & 665.6 & 7.01 & 2.75 \\
\hline & 2.4 & 7.90 & 11.47 \\
\hline \multirow[t]{3}{*}{ GA } & 24 & 6.35 & 5.18 \\
\hline & 480 & 7.41 & 5.27 \\
\hline & 1.74 & 11.28 & 17.60 \\
\hline \multirow[t]{3}{*}{ GB } & 17.4 & 5.42 & 11.81 \\
\hline & 348 & 6.62 & 0.95 \\
\hline & 1.176 & 13.44 & 8.25 \\
\hline \multirow[t]{2}{*}{ GC } & 11.76 & 6.40 & 6.90 \\
\hline & 235.2 & 7.92 & 2.31 \\
\hline
\end{tabular}

suggested that botanical drug products should be investigated with regard to blood levels of known representative markers, active constituents, and major chemical constituents. The pharmacokinetic studies of G. biloba and its preparations were mostly implemented in rats, which most only for flavonols or lactones of single preparation [13-17]. In this paper, a UPLC-ESI-MS/MS method for simultaneous determination of three flavonoids (KMF, QCT, and ISR) and four lactones (GA, GB, GC, and $\mathrm{BB}$ ) in beagle dog plasma was described for the first time. In addition, the current method also offers other advantages over existing methods, such as shorter analysis time (4.0 min). This method can be applied to a pharmacokinetic study of different $G$. biloba L. extract preparations after oral administration to beagle dog. 
Table 5: Stability of the analytes in beagle dog plasma $(n=3)$

\begin{tabular}{|c|c|c|c|c|}
\hline \multirow[t]{2}{*}{ Compound } & \multirow[t]{2}{*}{$C\left(\mathrm{ng} \cdot \mathrm{mL}^{-1}\right)$} & \multirow{2}{*}{$\begin{array}{c}\text { Room temperature } \\
\text { stability in } 6 \mathrm{~h}\end{array}$} & \multicolumn{2}{|l|}{ RSD / $\%(n=3)$} \\
\hline & & & $6 \mathrm{~h}$ & $12 \mathrm{~h}$ \\
\hline \multirow{3}{*}{ KMF } & 3.08 & 1.27 & 0.60 & 7.20 \\
\hline & 30.8 & 4.28 & 2.49 & 2.28 \\
\hline & 616 & 3.50 & 0.74 & 4.83 \\
\hline & 0.6 & 11.35 & 9.51 & 11.97 \\
\hline \multirow{3}{*}{ QCT } & 6 & 1.23 & 1.20 & 1.27 \\
\hline & 120 & 6.70 & 4.70 & 5.53 \\
\hline & 0.492 & 4.14 & 5.30 & 8.59 \\
\hline \multirow[t]{3}{*}{ ISR } & 4.92 & 1.97 & 1.27 & 1.83 \\
\hline & 98.4 & 1.09 & 2.22 & 2.01 \\
\hline & 3.328 & 4.24 & 6.43 & 5.33 \\
\hline \multirow[t]{3}{*}{ BB } & 33.28 & 2.21 & 3.14 & 0.62 \\
\hline & 665.6 & 1.95 & 0.77 & 0.72 \\
\hline & 2.4 & 2.94 & 13.68 & 3.34 \\
\hline \multirow[t]{3}{*}{ GA } & 24 & 3.87 & 4.24 & 3.60 \\
\hline & 480 & 4.11 & 4.71 & 1.06 \\
\hline & 1.74 & 3.31 & 7.20 & 6.77 \\
\hline \multirow[t]{3}{*}{ GB } & 17.4 & 1.12 & 1.54 & 1.33 \\
\hline & 348 & 1.43 & 2.15 & 2.13 \\
\hline & 1.176 & 3.68 & 3.90 & 10.35 \\
\hline \multirow[t]{2}{*}{ GC } & 11.76 & 2.22 & 1.63 & 1.13 \\
\hline & 235.2 & 3.46 & 2.06 & 4.04 \\
\hline
\end{tabular}

\section{CONCLUSION}

The developed methods meet the requirements for biological sample analysis.

They can be applied to the pharmacokinetic studies of kaempferol, quercetin, isorhamnetin, ginkgolides $\mathrm{A}$, ginkgolides $\mathrm{B}$, ginkgolides $\mathrm{C}$ and bilobalide in dog plasma when Ginkgo leaf preparations are administered.

\section{ACKNOWLEDGEMENT}

This work was supported by the National Natural Science Foundation of China (NO. 81073057), Innovation Team Development Program of Beijing University of Chinese Medicine (no. 2011CXTD-13) and National Basic Research Program of China (973 Program, no. 2012CB724000).

\section{REFERENCES}

1. Satoh $H$, Nishida S. Electropharmacological actions of Ginkgo biloba extract on vascular smooth and heart muscles. Clin Chim Acta. 2004; 1-2: 13-22.

2. Ude C, Paulke A, Schubert-Zsilavecz M, Wurglics $M$. Chemistry, pharmacokinetics and metabolism of ginkgo extract. Pharm Unserer Zeit. 2009; 5: 418423.

3. Kennedy DO, Haskell CF, Mauri PL, Scholey AB. Acute cognitive effects of standardised Ginkgo biloba extract complexed with phosphatidylserine. Hum Psychopharm Clin. 2007; 4: 199-210.
4. Koh PO. Identification of proteins differentially expressed in cerebral cortexes of Ginkgo biloba extract (EGb761)-treated rats in a middle cerebral artery occlusion model--a proteomics approach. Am J Chin Med. 2011; 2: 315-324.

5. Lang D, Ude C, Wurglics $M$, Schubert-Zsilavecz M, Klein $J$. Brain permeability of bilobalide as probed by microdialysis before and after middle cerebral artery occlusion in mice. J Pharm Pharm Sci. 2010; 4: 607614.

6. Ude C, Schubert-Zsilavecz M, Wurglics M. Ginkgo biloba Extracts: A Review of the Pharmacokinetics of the Active Ingredients. Clin Pharmacokinet. 2013; 9: 727749.

7. Westman J, Drieu K, Sharma HS. Antioxidant compounds EGB-761 and BN-520 21 attenuate heat shock protein (HSP $72 \mathrm{kD}$ ) response, edema and cell changes following hyperthermic brain injury. An experimental study using immunohistochemistry in the rat. Amino Acids. 2000; 1: 339-350.

8. Gray $D$, LeVanseler K, Pan M. Determination of flavonol aglycones in Ginkgo biloba dietary supplement crude materials and finished products by high-performance liquid chromatography: single laboratory validation. $J$ Aoac Int. 2005; 3: 692-702.

9. Gray D, LeVanseler K, Meide P, Waysek EH. Evaluation of a method to determine flavonol aglycones in Ginkgo biloba dietary supplement crude materials and finished products by high-performance liquid chromatography: collaborative study. J Aoac Int. 2007; 1: 43-53.

10. Sun $Y, L i W$, Fitzloff JF, van Breemen RB. Liquid chromatography/electrospray tandem mass 
spectrometry of terpenoid lactones in Ginkgo biloba. J Mass Spectrom. 2005; 3: 373-379.

11. Zhao $Y$, Sun $Y$, Li C. Simultaneous determination of ginkgo flavonoids and terpenoids in plasma: ammonium formate in LC mobile phase enhancing electrospray ionization efficiency and capacity. J Am Sco Mass Spectrom. 2008; 3: 445-449.

12. Yao $X$, Zhou GS, Tang YP, Qian YF, Guan HL, Pang $H$, Zhu S, Mo X, Su SL, Jin C, Qin Y, Qian DW, Duan $J A$. Simultaneous quantification of flavonol glycosides, terpene lactones, biflavones, proanthocyanidins, and ginkgolic acids in Ginkgo biloba leaves from fruit cultivars by ultrahighperformance liquid chromatography coupled with triple quadrupole mass spectrometry. Biomed Res Int. 2013: 582-591.

13. Chen F, Li L, Xu F, Sun Y, Du F, Ma X, Zhong C, Li X, Wang $F$, Zhang $N, L i C$. Systemic and cerebral exposure to and pharmacokinetics of flavonols and terpene lactones after dosing standardized Ginkgo biloba leaf extracts to rats via different routes of administration. Brit J Pharmacol. 2013; 2: 440-457.
14. Chen ZP, Sun J, Chen HX, Xiao YY, Liu D, Chen J, Cai $H$, Cai BC. Comparative pharmacokinetics and bioavailability studies of quercetin, kaempferol and isorhamnetin after oral administration of Ginkgo biloba extracts, Ginkgo biloba extract phospholipid complexes and Ginkgo biloba extract solid dispersions in rats. Fitoterapia. 2010; 8: 1045-1052.

15. Rangel-Ordonez L, Noldner $M$, Schubert-Zsilavecz $M$, Wurglics M. Plasma levels and distribution of flavonoids in rat brain after single and repeated doses of standardized Ginkgo biloba extract EGb 761(R). Planta Med. 2010; 15: 1683-1690.

16. Rossi R, Basilico F, Rossoni G, Riva A, Morazzoni P, Mauri PL. Liquid chromatography/atmospheric pressure chemical ionization ion trap mass spectrometry of bilobalide in plasma and brain of rats after oral administration of its phospholipidic complex. J Pharmaceut Biomed. 2009; 2: 224-227.

17. Zhang $Q$, Wang GJ, A JY, Wu D, Zhu LL, Ma B, Du Y. Application of GC/MS-based metabonomic profiling in studying the lipid-regulating effects of Ginkgo biloba extract on diet-induced hyperlipidemia in rats. Acta PharmSinic. 2009; 12: 1674-1687. 